\title{
From a subtractive to multiplicative approach , two concept-driven interactive pathways on the selective absorption of light.
}

\section{Laurence Viennot ${ }^{1}$}

PRES Sorbonne Paris Cité, Université Paris Diderot, LDAR

France

E-mail: laurence.viennoteuniv-paris-diderot. fr

\begin{abstract}
This contribution is devoted to a type of teaching scenario - concept-driven interactive pathways - aiming at developing conceptual understanding and critical faculty in students. The examples will bear on interaction between light and matter at university level (absorption by pigments, liquids and the atmosphere) and will illustrate how formal simplicity may be compatible with an exigent approach linking a search for conceptual coherence and a critical analysis.
\end{abstract}

Frontiers of Fundamental Physics 14

FFP14

15-18 July 2014

Aix Marseille University (AMU) Saint-Charles Campus, Marseille

${ }^{1}$ Speaker

(c) Copyright owned by the author(s) under the terms of the Creative Commons Attribution-NonCommercial-ShareAlike Licence. 
From a subtractive to multiplicative approach

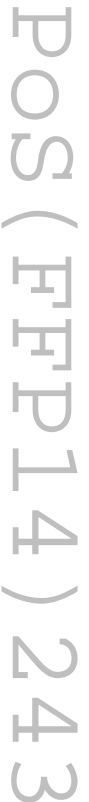




\section{Introduction}

As argued in a previous talk (plenary: Viennot, these proceedings), alarming reports in several countries ([1], [2]) give credit to the idea that it is important to stress links and consistency when teaching physics, instead of too exclusively centering on students' competencies. The objective of fostering critical faculty in our students, in particular, should be seen as interlaced with that of developing conceptual structuring. This idea is backed up by recent and converging experiments suggesting that, when confronted with very incomplete explanations, students need to reach a threshold of comprehension of the topic in play before liberating their critical ability. Although the interest of aiming at a co-development of critical stance and comprehension seems nearly obvious and is claimed in many official reports, it is often denied in current practice at secondary school level, particularly in France, as witnessed by the reports just quoted.

\section{A teaching format: concept-driven interactive pathways}

The expression "Concept-driven interactive pathway" (CDIP) designates a type of teaching sequence with the following characteristics [3].

- It is designed with the goal of facilitating students' access to the understanding of a given conceptual content.

- It is interactive, implying teacher-student or teacher-group interaction. It may comprise phases like: exploring and discussing students' ideas, asking for argued predictions or diagrams and discussing these with students, letting students construct and analyze experimental results, injecting new ideas in a transmissive style, having students' criticize documents, etc.

- It organizes a pathway, that is, a step-by-step process designed to help students progress toward the desired target. Although the structure of the pathway is mainly concept-driven, the development of transversal abilities, such as critical faculty, is also favoured.

With such a format, the particular spotlighting of the content is of crucial importance, as illustrated below. Two CDIPs on the absorption of light, each intended for an interaction of about one hour, have been designed and implemented. Depending on the targeted audience and school constraints, the first one, centering on the absorption of light by pigments ([4], [5]), may constitute a preparatory step for the second one, about filtering process ([3], [6]), or each may be implemented alone. Here, for sake of brevity, we focus on the conceptual structure of these CDIPs, while giving an idea of the students' response in terms of critique.

\subsection{The absorption of light: core ideas}

Globally these two pathways are intended to spotlight the following conceptual targets.

- The absorption of light by pigments or filters is not an all-or-nothing process. This idea is contrary to what is suggested by the current rules for colour phenomena, such as "red pigments absorb blue light", etc.

- It is a multiplicative process, involving multiplication by numbers smaller than 1 .

- It is selective, that is, it depends on the wavelength. 
These investigations were conducted on the basis of interviews with prospective teachers at university, the first one (CDIP1) with 8 students in the third year, the second one (CDIP2) with 6 students in the fourth year. Our investigation with the first pathway (CDIP1) revealed that the interviewees were destabilized when the common binary rules - a pigment absorbs, or does not, such and such a part of the spectrum of white light - turned out to be inappropriate, as when the impact of a red laser beam on a green pigment is quite visible. Moreover, we observed that they had considerable difficulty in understanding what it means to use percentages to analyze the process of absorption. These results provided the arguments at the basis of the construction of the second pathway (CDIP2), which is briefly described hereafter.

\subsection{Lights and filters (CDIP2)}

The results of the first experimentation inspired us to investigate possible ways to help students understand the multiplicative status of absorption. We chose to use filters, and made the hypothesis that the dependence of absorption on thickness might be an anchoring aspect for the targeted comprehension. Indeed, to understand the role of the successive, equally thick, layers of a filter, one has to understand that if one layer multiplies the incident intensity of light by, say 0,95 , the second will let $0,95^{*} 0,95$ of this initial intensity pass.

Table 1 displays the steps of an interview (about an hour) designed on this basis. During the first phase, the interviewees were reminded of the classical rules, and were given a corresponding table. Then they were asked which mathematical operation came to their mind in this respect. All responded "subtraction". Then, they were shown a slide with a slit crossed by filtering strips of increasing thicknesses, made of one, two, three, etc., layers of a light yellow plastic sheet (Figure 1).

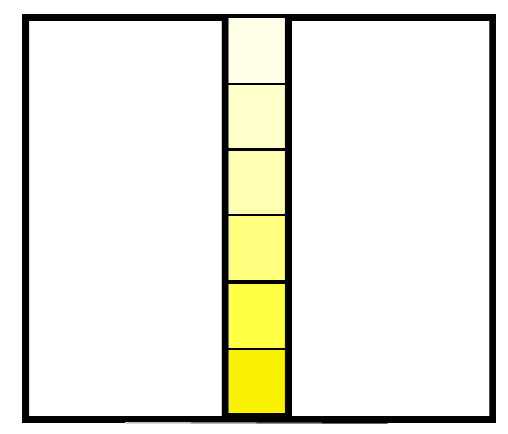

Figure 1. A slide $(5 \mathrm{~cm} \times 5 \mathrm{~cm})$ with a vertical slit (width about $1 \mathrm{~mm})$, covered with one, two, three, ..., six horizontal strips made of transparent and thin plastic: light yellow, or light pink

Then, they were given a curve of transmission for one layer and asked to draw the curve for a strip with two or three superposed layers (Figure 2). 


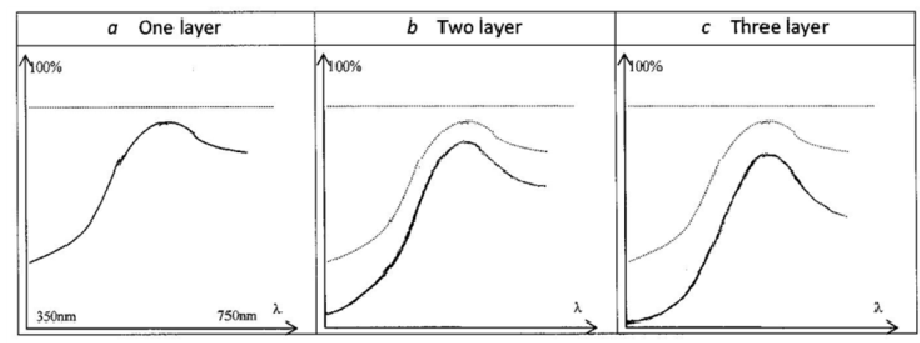

Figure 2. Given the transmission curve for one filtering layer, strips with two or three superimposed layers don't have a transmission curve of a similar shape

The drawings and the comments that were collected in this phase show how salient the idea of non-selective subtraction was, in other terms, the downward translation of the transmission curve proposed for one layer (5 students out of 6). The following conceptual target was to use the idea of multiplication to realize and explain the deformation of the transmission curves with thickness. Then an experiment proposed by the interviewer was performed to show the spectra of light transmitted by each strip of the slide shown in Figure 1. With this object, and also another one made of pink-magenta plastic, some parts of the spectrum (red and green) of the transmitted light seemed nearly unaffected by thickness whereas the blue part disappeared with the three-layer strip (Figure 3).

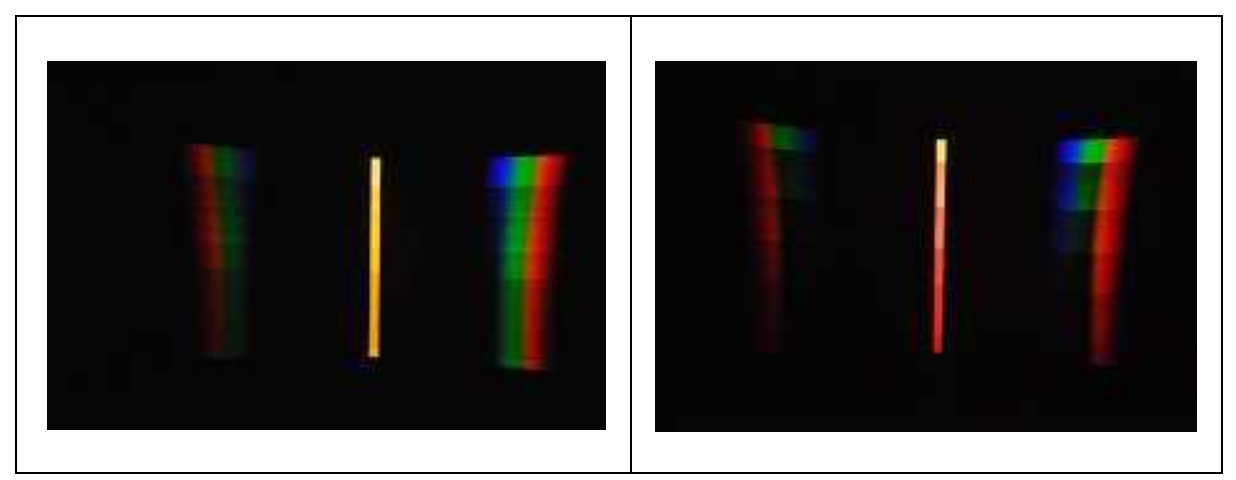

Figure 3. Photos of spectra obtained for two slits equipped with transversal strips (resp. yellow and magenta) of increasing thickness: one, two, three, ... layers superposed. (Grating $600 \mathrm{l} / \mathrm{mm}$ )

The discussion with the interviewer was more or less laborious, until all the interviewees manifested their comprehension of the conceptual target. The subsequent phases were devoted to the transfer of this new knowledge to other situations, a liquid and a gaseous filter, respectively pumpkin seeds oil and the atmosphere. In these two cases, the change in colour of the transmitted light was explained by the interviewees, after discussion, on the basis of the initially provided transmission curve (Fig. 4a: simplified curve after [7], Fig 4b after [8]). Once the possibility of seeing oil or the atmosphere as filters was admitted, it became clear to the students that successive multiplications would come down to selecting the part of the spectrum where the rate of transmission was the highest, i.e. in both cases the "red" part. 


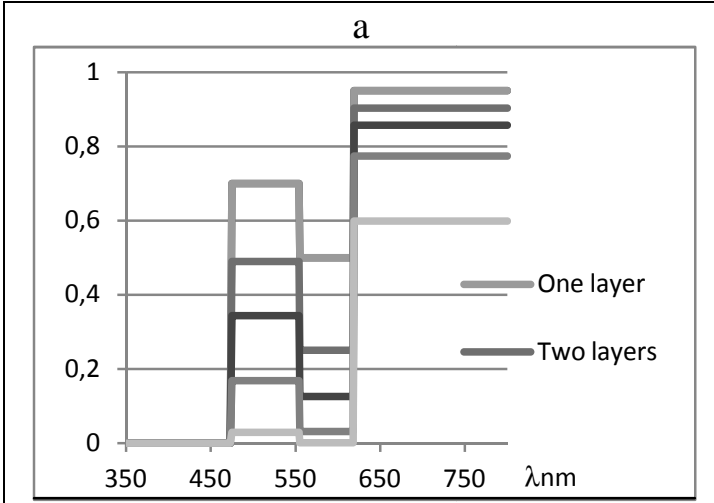

$\uparrow$ Transmission curve of one, two, three, four, five, ten successive layers of pumpkin seeds oil.

$\downarrow$ Pictures of thinner or thicker layers illuminated in white light:

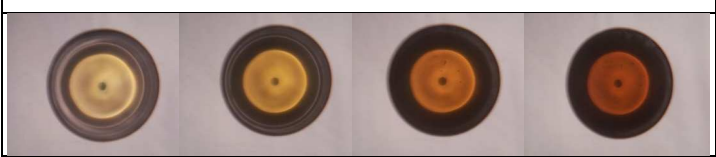

Figure 4. Transforming the transmission curves of a "thin" layer of fluid (a: pumpkin seeds oil [7], b: atmosphere [8]) to find that of a thick layer.

Table 1. Structure of concept-driven interactive pathway CDIP 2

\begin{tabular}{|c|c|c|c|}
\hline Phase & Our conceptual targets and questions & Material setting & $\begin{array}{l}\text { Main aspects of the interaction } \\
\text { (planned and/or expected) }\end{array}$ \\
\hline Rem & $\begin{array}{l}\text { Students are reminded of the classical } \\
\text { rules } \\
\text { First observation of their reactions } \\
\text { Question: which operation comes to } \\
\text { your mind:+,-,*,/? }\end{array}$ & A colour mixer & $\begin{array}{l}\text { The students appropriate the classical rules; } \\
\text { predictions on this basis, observation, } \\
\text { discussion, recapitulation. } \\
\text { Table of rules left to students } \\
\text { Question "which operation ...?" }\end{array}$ \\
\hline Filt- $a$ & $\begin{array}{l}\text {-Draw the curves accounting for the } \\
\text { transmission of light through two, then } \\
\text { three layers of the same material: } \\
\text { Do students just translate the first curve } \\
\text { downwards, or do they/how do they } \\
\text { change the shape of the curve? }\end{array}$ & $\begin{array}{l}\text { 日 } \\
\text { + Device to project } \\
\text { spectra of the light }\end{array}$ & Predictions with arguments \\
\hline Filt-b & $\begin{array}{l}\text { Performing the experiment: } \\
\text { Do they change their curves? Formulate } \\
\text { a conclusion explicitly using selective } \\
\text { multiplication? }\end{array}$ & $\begin{array}{l}+ \text { Device to project } \\
\text { spectra of the light } \\
\text { transmitted through each } \\
\text { strip } \\
\text { Spectra observed }\end{array}$ & $\begin{array}{l}\text { Students asked to reconsider the curves, to } \\
\text { account for the disappearance of "the blue" : } \\
\text { strongly guided discussion }\end{array}$ \\
\hline Oil & $\begin{array}{l}\text { Observe colours of the oil, then apply a } \\
\text { multiplicative procedure to the curve } \\
\text { proposed by the interviewer to account } \\
\text { for these colours }\end{array}$ & $\begin{array}{l}+ \text { Sensitivity curves of the } \\
\text { cones on transparency. }\end{array}$ & $\begin{array}{l}\text { The interviewer } \\
\text {-provides help for calculation. } \\
\text {-explains how to use the sensitivity curves } \\
\text { of the cones.. }\end{array}$ \\
\hline Atm & $\begin{array}{l}\text { See the situation as a filtering case. } \\
\text { Transform the curve provided by the } \\
\text { interviewer for "one layer" }\end{array}$ & 0 & $\begin{array}{l}\text { The interviewer provides help for } \\
\text {-interpretation of the situation as a case of } \\
\text { filtering } \\
\text { - calculation }\end{array}$ \\
\hline Gene & $\begin{array}{l}\text { Ask about a function accounting for the } \\
\text { changes of intensity observed }\end{array}$ & & $\begin{array}{l}\text { Input from the interviewer: } \\
\text { (selective) exponential decrease }\end{array}$ \\
\hline$M c a$ & Global evaluation of the design & & Interviewees express feelings \\
\hline
\end{tabular}




\subsection{Students' response: from common ideas to restrospective critique}

In terms of comprehension, the prevalence and the resistance of the idea of - implicitly uniform - subtraction was very impressive.

- Int (Interviewer): What did you use when constructing your answer, a line of reasoning founded on which type of operation?

- Subtraction, mainly.

Or else

- We add subtractions.

The comments finally attesting to a real comprehension were all the more striking.

- Given that it is proportional, ... (adding filters) we will end by selecting the spectral band of greatest transmission factor.

- Even after having done this (a multiplication) right from the beginning, I wouldn't have interpreted this as a multiplication.

A final observation is worth pinpointing here. Beyond numerous expressions of satisfaction, we note the emergence of some meta-cognitive judgments.

- We've just seen that differences were majored when layers were added. I wouldn't have spontaneously used the word multiplication, I did not reason like that before coming here. (...) Perhaps, I would use the operation with the right data, but if I was asked for an explanation, I would never have used the word multiplication.

We find here an echo of several comments collected during a subsequent workshop in a meeting of the European Science Education Research Association [9], which was framed on this CDIP.

-The use of different thicknesses, we usually do it with only one and I had the idea of subtraction.

-It made me think about things I knew about intuitively perhaps, but I still think it was as if I did not know about them previously.

\section{Recapitulation and final remarks}

These two concept-driven interactive pathways have several common features. They are designed on the basis of a very fundamental idea, sometimes referred to by the interviewees as a "tough idea". The multiplicative nature of the process of absorption ultimately leads to the exponential dependence of intensity on the crossed thickness. Although this was hardly discussed in the short time we had, the process of absorption is multiplicative because it is statistical. For all of that, the formal complexity, which may seem very little, comes down to that of successive multiplications. It may also seem not to constitute the least "new idea", despite the students' recurrent comments. It is not "new physics", but it is a spotlighting of physics that takes some distance from the most prevalent teaching rituals, i.e. the binary rules of the absorption of light by filters or pigments still used without any discussion [10]. Students' ideas are taken into account, with the goal of extending the range of their line of reasoning when they pass from a view limited to subtraction to a more fruitful multiplicative approach. The decision was also taken to underline the links that physics enables us to establish: A multiplicative process accounts for changes in light which interacts with solids, liquids and 
gases. In terms of formal complexity, the price to pay is moderate. Simplicity is still favoured via the choice of equally thick layers and a discrete approach to exponential function. At the same time, simplification is kept under control as consistency is not seriously at risk.

The content driven interactive pathways just described illustrate, we think, the merits of a design emphasizing consistency and conceptual links, as well as spurring an active engagement on the part of the students. Although the adjective "new" may seem deceptive, it means that attention is given to aspects of physics that have been commonly disregarded, or kept implicit. One may wonder what possible obstacles may block this open reconsideration of content. Among good candidates, we suggest: a lack of distance with respect to rituals, an exclusive centering on students' ideas, excessive belief in (and focusing on) the power of new methods, the possible identification of «more rigorous » with «boring », and the common view that what is good for teachers cannot be good for their students. Clearly, more research is needed to give more substance to these assertions.

\section{References}

[1] T. Zabulon, On the linking between secondary teaching and higher education in physics and chemistry, 6le National Conference of Union of Physics and Chemistry Teachers (UdPPC), BUP (2013), 2011-2016.

[2] S. Lie, C. Angell \& A. Rohatgi, Interpreting the Norwegian and Swedish trend data for physics in the TIMSS Advanced Study, Nordic Studies in Education, 32 (2012), 177-195.

[3] L. Viennot \& C. de Hosson, From a Subtractive to Multiplicative Approach, A Concept-driven Interactive Pathway on the Selective Absorption of Light, International Journal of Science Education (2014), DOI: 10.1080/09500693.2014.950186

[4] L. Viennot \& C. de Hosson, Beyond a dichotomic approach, the case of colour phenomena. International Journal of Science Education, 34:9 (2012), 1315-1336

[5] L. Viennot \& C. de Hosson, Colour phenomena and partial absorption, Published by the MUSE group (More Understanding with Simple Experiments), EPS-PED (2012). http://www.eps.org, Education, MUSE.

[6] L. Viennot, Colour phenomena and selective absorption: the role of thickness of absorbing medium, Published by the MUSE group, EPS-PED (2013). http://www.eps.org/, Education, MUSE.

[7] S. Kreft \& M. Kreft, Physicochemical and physiological basis of dichromatic colour, Naturwissenschaften 94 (2007), 935-939.

[8] M. Vollmer \& S. D. Gedzelman, Colours of the Sun and Moon: the role of the optical air mass, European Journal of Physics 27 (2006), 299-309.

[9] L. Viennot \& A. Mueller, The selective absorption of light, Physics Education, 48:6 (2013), 700701.

[10] A.R. Mota \& J.M.B. Lopes dos Santos, Addition table of colours: additive and subtractive mixtures described using a single reasoning model. Physics Education, 49:1 (2014), 61-66. 